\title{
The Role of Environment As Third Teacher Towards The Development Of Educational Space For Dyslexic Children
}

\author{
Alice Sabrina Ismail \\ Department of Architecture, Faculty of Built Environment and Survey, Universiti Teknologi Malaysia, 81310 UTM Johor Bahru, Johor, Malaysia \\ Email: b-alice@utm.my \\ Nur Syaza Zureena Zulkurnain \\ Department of Architecture, Faculty of Built Environment and Survey, Universiti Teknologi Malaysia, 81310 UTM Johor Bahru, Johor, Malaysia
}

\begin{abstract}
Educational space that responds towards disable learning student needs is vital for a conducive learning environment. This paper explores on learning spaces for disable children namely the dyslexic in reference to the role of environment as the third teacher towards designing an appropriate educational space to fulfil their needs. Past literature on dyslexia in Malaysia much focuses on the pedagogy and teaching methods rather than discusses the issue of providing better learning space design that caters to the need of dyslexic children towards their psychological well-being. To conduct this study, the qualitative method involving case study as research strategy is used to establish the appropriate learning space design attributes for the dyslexic children. Data sources for this study are obtained from direct observation on three selected case studies of prominent learning disability school found in the global context. There are two key factors that contributed in the learning process and development of learning disability student namely the dyslexic children. These are the non-physical elements comprises of visual cues, auditory, tactile and kinaesthetic approaches as well as physical elements encompasses of density and size including spatial layout arrangement. Findings of the study are in the form of established referential guideline design to inform future designers, builders, education providers and related authority on how to build a conducive learning space environment for the dyslexic children. This is vital in improving the quality of public education infrastructure for dyslexic students in the Malaysian context towards their betterment in the future.
\end{abstract}

\section{Article History}

Received : 7 February 2019

Received in revised form : 24 March 2019

Accepted : 17 April 2019

Published Online : 30 April 2019

Keywords:

Learning space design, dyslexia children, environment as third teacher, learning disability

\section{Corresponding Author Contact:}

b-alice@utm.my

DOI: $10.11113 /$ ijbes.v6.n2.356

(C) 2019 Penerbit UTM Press. All rights reserved

\section{Introduction}

Educational space refers to learning environment setting, a place in which teaching and learning occurs (Goouch, 2008). This space therefore, not only limited to indoor physical parameters but also outdoor spaces as well. The existence of this educational space nevertheless, must also be supported with actual or virtual technology application to ensure students obtained better level of education with positive physical, emotional and spiritual enrichment (Brown \& Long, 2006). Nonetheless, the existence of conducive educational space in most of Malaysian public schools is still lacking and undermined (Yacob, 2005). This issue however, is much crucial namely in schools that cater for special needs children varying, from 'mild' learning disability cases like dyslexia and ADHD to more severe disabilities like 
autism, Down syndrome, mental retardation, physical retardation and many others (Nasir \& Efendi, 2017). From observation and scholarly review (2010-2019), Malaysian schools still lacking in providing better education in terms of curriculum as well as building facilities involving conducive learning space to cater for the needs of these special children with learning disability (Ahmad, Shaari, Hashim, \& Kariminia, 2015; Ali, Mustapha, \& Jelas, 2006; Amar, 2008; Jelas \& Mohd Ali, 2014; Muzaliha et al., 2012; Oga \& Haron, 2012; Tan, 2015). According to survey, it is estimated that 1 in every 20 children may have learning disability condition due to hereditary, teratogenic issues, medical and environmental factors (Malaysia, 2014).From all type of learning disability mentioned above, dyslexic however, is viewed as the most crucial issue that need to be greatly addressed by all involved parties at the government level, education provider and parents' perspective (Malaysia, 2014). Since there is lack of awareness among society, numbers of dyslexic patient namely among children is stated to rise each year in Malaysia (Malaysia, 2014). Malaysian statistics indicated that from total estimation of 4.5 million children below the age of 18 years old in year 2017, almost 5\% have learning incapacity due to reading disability known as dyslexia (Sinnadurai, 2018). Although there are no specific cure or permanent solution to curb dyslexia, guidance and care as well as extra attention like betterment of education facilities and conducive learning environment is important that may provide huge difference for dyslexic patient namely amongst children(Adnan \& Hafiz, 2001)

In general, there are five main issues relating to learning disability focusing on dyslexia in the Malaysian context as follows. First, lack of building design approaches comprising of spatial layout and form making as well as facilities readiness to cater for dyslexic patient needs. In this sense, in terms of facilitating, there is no proper physical setting to accommodate those with dyslexia. In brief, there is no well-designed multi-sensory environment yet in Malaysia that can facilitate those with dyslexic (Subramaniam, Mallan, \& Mat, 2013). Second, is from the aspect of financial resources constraint that resulted to ineffective human capital development and management to monitor dyslexic individuals (Ta, Wah, \& Leng, 2011). Third, lacking in appropriate teaching materials to help and rehabilitate the dyslexic patient namely at the early age (Rahman, Mokhtar, Alias, \& Saleh, 2012). Fourth, lack of structured program on early intervention or standardized instrument which includes all categories of impairment condition to identify those with dyslexic consisting of three phases which are at pupils level, teachers role and parents point of view (Osman, Yahaya, \& Ahmad, 2015). Fifth, lack of comprehensive guidelines implementation and development for an equitable examination system and procedures for those with reading disabilities or dyslexic (Dzalani \& Shamsuddin, 2014).

From all of the above, the most prominent issue that requires attentive attention is in the aspect of infrastructure establishment for the dyslexic children. In this sense, more buildings that function as educational provider must be made accessible and disabled-friendly, especially for children with reading and learning impairment to facilitate their learning processes.

Furthermore, to date, there are only few literature that discusses on the issue of providing better learning space design that caters to the need of dyslexic children in the Malaysian context towards their psychological well being. This is because current studies only focuses on five main areas (Ahmad et al., 2015; Ali et al., 2006; Amar, 2008; Jelas \& Mohd Ali, 2014; Muzaliha et al., 2012; Oga \& Haron, 2012; Tan, 2015). First, learner's characteristic on dyslexic children. Second relating to instructional approach and method to educate dyslexic children. Third, reviews on learning materials to assist dyslexic children. Fourth, emphasizing on ICT tools for special teaching needs. Fifth, focus on pedagogy or method on teachers' role and perspective to become trainers or caregivers for dyslexic patients. From the findings of literature review above, it can be concluded that special attention need to be emphasis on building design that may solve different obstacles faced by students with learning difficulties like dyslexia. This aspect is important because physical environment of the classroom may influence dyslexic children mind set as well as encourages optimal learning in cultivating constructive knowledge culture among them. This study therefore aims to investigate the condition and problems of existing schools in Malaysia whether or not better learning space for dyslexic children development are provided, focusing only at the primary level. The outcome of the study will be on proposing a design guideline framework on conducive learning space for dyslexic children. The scope of the study involves children at primary level from age 7-12 as they are at the early phase of learning development that are susceptible to behavioural change or adaptation. In this sense, the childhood phase is viewed by many scholars and psychologists as a vulnerable age that can be nurtured in terms of cognitive and psychomotor development (Rao et al., 2017). This is vital namely for ensuring positive growth and wellbeing of disable children to be well knowledgably equipped in terms of literacy, numeracy and skills development.

For the benefit of the study and to fulfil the objectives, section two is divided into three parts. Firstly, will define the type, characteristic and behavioural pattern of dyslexic patient. Second, reviewing on learning approaches and strategies for dyslexic children. The third part will elucidate on the issues, definition as well as characteristics of learning space of current special schools in Malaysia, followed by the importance of learning space design in shaping dyslexia children behaviour and psychology.

\section{Literature Review}

\subsection{Definition And Types Of Dyslexia}

Dyslexia in general terms is defined as disorders that involve difficulty in learning to read or interpret words, letters, and other symbols, but that do not affect general intelligence(Lyon, Shaywitz, \& Shaywitz, 2003).In other words, dyslexia is stated as a spectrum learning disability involving reading fluency, writing and phonological difficulties (Lyon et al., 2003). There are no specific cure for dyslexic patient but they can improve their development in literacy and numeracy skill with more intensive instruction and motivational learning surroundings equipped with appropriate facilities. Dyslexia is also referred to as a learning disability, which does not have physically visible signs that can be detected during infants (Lyon et al., 2003). Dyslexia symptoms only can be detected when a child begins his or her education years when it involves process of reading, writing and conducting numerical skills. If untreated, it may disrupt and lessened their academic achievement of vocabulary and numeracy abilities due to poor phonological memory of visual object recognition and speech vocabulary which later resulted to poor social skills and interactions, frustration as well as low self -esteem. In long term this will affect their life time opportunities.

Scholars identifies that there are three types of dyslexia which are visual dyslexia (early stage), auditory dyslexia (medium stage) and deep dyslexia (severe stage)(Frith, 2017). The early stage is defined as phases that applies only to reading task. They only make errors when reading aloud and speaking while not making errors in silent reading. At this early stage, they manage to identify letters and their relative position but still have errors of letter migrations between words. Secondly, is the medium stage. This medium stage in general involve reading and speaking. At this stage, patient commonly make regularization errors in reading aloud. In this sense they typically have problem with accuracy and in comprehension which resulted to slower reading. Finally, is 
severe stage. At this phase, they could not understand the words they read although they can read aloud correctly. All three stages above nonetheless require attention from parents and teacher to help those with dyslexic to deal with their difficulties in a much proper approach. Although it is viewed that dyslexia much relates to individual achievement in terms of reading skills, many scholars also do agree that proper learning space and appropriate facilities supported by structured pedagogy may also influence dyslexic patient to develop, stimulate and improve their learning abilities (Frith, 2017). To understand this in depth, the next section will explain on learning strategies and approaches to improve the condition of dyslexic patient.

\subsection{Learning Approaches For Dyslexic - Environment As Third Teacher}

Dyslexic patient in general may share the same profile and weaknesses in terms of learning disability but in specific they require a variety of approaches and learning strategies to overcome the learning issues. This not only focuses on the implementation of proper pedagogy but also in terms of providing sound environment and surrounding to help their process of learning (Démonet, Taylor, \& Chaix, 2004). For instance, based on scholarly research, dyslexic patients whom are struggling with numeracy, usually have problems with directional confusion, sequencing problems, poor short-term a working memory, speed of working, cognitive style, anxiety, stress and self-image. Thus, they require the help of multisensory environment as pedagogical approaches to aid this type of dyslexia. This however, may be different with dyslexic patient whom has spelling difficulties because they have stronger visual senses and semantic ability. In other words, these category of individuals have higher learning abilities to understand new words by the visual strength combined with either kinesthetic and/or auditory channel. In this case, they require strong visual image such as big and colourful elements as well repeating patterns visibly shown within their learning sorroundings to help them remember and memorize. From this it is shown that physical learning setting may influenced the experience of an individual towards a form of exploration and collaborations. According to scholars, designing proper learning space and environment will attribute to almost 25\% of a student's achievement over their progress in their whole academic year (Nasir \& Efendi, 2017). This however, is much crucial namely for children with learning disability (Nasir \& Efendi, 2017).

In this case, the environment becomes the third teacher to facilitate disable learning children to discover variety materials while actively exploring, investigating and solving problems as one way in accomplishing active learning through play experiences (Strong-Wilson \& Ellis, 2007). As an example, by providing better environment for the children to thrive in indoor and outdoor learning space will trigger their senses to imagine, think, investigate, create and solving problem based on their experience. This in return will help them be more calm, have high esteem and engaged with society. From conducted literature studies it is found that there are two basic aspects of architectural aspects that needed consideration in establishing a better environment as third teacher to accommodate learning disable children with special needs in their learning process (Strong-Wilson \& Ellis, 2007). This involves the physical- setting, scale and proportion, materials and finishes adaptation and the non- physical aspects which are environmental considerations as follows (refer Table 1).

Table 1 Important aspects in designing learning spaces for learning disable children obtained from literature review (Strong-Wilson \& Ellis, 2007)

\begin{tabular}{|c|c|c|}
\hline $\begin{array}{c}\text { Physical } \\
\text { aspects }\end{array}$ & Features & Approaches \\
\hline Setting & $\begin{array}{c}\text { Comfortable classroom } \\
\text { setting and furniture layout }\end{array}$ & $\begin{array}{l}\text { Combinations of group and individual setting for flexibility and } \\
\text { privacy. }\end{array}$ \\
\hline $\begin{array}{l}\text { Scale and } \\
\text { Proportion }\end{array}$ & $\begin{array}{l}\text { Appropriate class size and } \\
\text { density }\end{array}$ & $\begin{array}{l}\text { Appropriate size to ease movements, comfort and wayfinding } \\
\text { will creates independency for the children in their learning } \\
\text { spaces. }\end{array}$ \\
\hline $\begin{array}{l}\text { Materials and } \\
\text { finishes } \\
\text { adaptation }\end{array}$ & $\begin{array}{l}\text { Suitable Multisensory aspects } \\
\text { - visual, touch, smell, } \\
\text { auditory }\end{array}$ & $\begin{array}{l}\text { Displaying tactile decorated walls, bright warm or cool colors } \\
\text { soft stimuli with appropriate materials and finishes } \\
\text { implementation will spark the children's interests towards } \\
\text { learning and enhance the sense of arrival. Transparency } \\
\text { throughout the space using mirrors, windows, internal glass } \\
\text { wall, glass objects, transparent film, large plastic sheets will } \\
\text { promote creativity and exploration. }\end{array}$ \\
\hline $\begin{array}{l}\text { Non Physical } \\
\text { aspects }\end{array}$ & Features & Approaches \\
\hline $\begin{array}{l}\text { Environmental } \\
\text { Integration }\end{array}$ & $\begin{array}{l}\text { Accommodating users' } \\
\text { health and wellbeing - } \\
\text { Natural daylighting and } \\
\text { shading, air quality control, } \\
\text { comfort room temperature } \\
\text { and suitable acoustic level }\end{array}$ & $\begin{array}{l}\text { Indoor and outdoor relation, learning spaces near to the } \\
\text { courtyard will have clear visibility, usage of appropriate } \\
\text { materials, natural lighting at core area with different height of } \\
\text { space openings create conducive learning ambience }\end{array}$ \\
\hline
\end{tabular}

In sum, the above had briefly outlined that thoughtful learning experience for disable children is linked with the stimulating learning environment that affects physical, emotional and cognitive readiness of the individual on a new learning task. This is vital to prepare the disable learning children for a much promising adulthood. However, the current special schools namely in the Malaysia context still lacking and undermined in providing better learning environment specifically for the learning disable children. Therefore, the design of current learning setting in Malaysia should be shifted from traditional type for a more holistic approach emphasizes on the physical environment as third teacher to help child's development 
especially for children with dyslexia. During live case observation and conducted interviews, there is no specific school built by private or the public government to cater for learning disable children. From Ministry of Education statistics it is estimated that a total of 314,000 students diagnosed to have dyslexia in Malaysia (Nasir \& Efendi, 2017). Many of these students are placed in remedial classes with other learning difficulties students since there are limited number of rehabilitation services for children with dyslexia in the country (Nasir \& Efendi, 2017). In other words, as a common practice, this learning disable children will enter the public government schools and placed in kelas khas or remedial class but separated from normal children or they enrolled in privately funded individual learning centres operated in rented shop houses or office buildings. Due to this matter it resulted to many disadvantages for the learning disable children to obtain better facilities and sound environment for them to improve their condition. To elaborate on this matter, next section will highlight the existing condition of learning spaces and form making in current Malaysia's schools for learning disable children that needed consideration and change in the future.

\subsection{Problem of Learning Spaces and form making in Malaysian Schools}

In general, there are three aspects that may influence learning process. First is the student-teacher relationship, second is in terms of management aspect and thirdly, is the classroom condition or learning environment. Nonetheless, learning spaces are the most important space that forms the backbone of school design planning. This is because learning is defined as an identification process that can give an understanding of knowledge and experience whether formally or informally. Studies shown that in Malaysian school, students from the age of 7 to 12 years old will spent an average of 25 hours per week in learning environment like school. This learning environment is defined as classroom where the learning process takes place involving physical and non physical elements in order to produce a balance context in terms of psychological and pedagogical aspects which give impacts on the student's behavior and achievements. In reference to this, the physical and non physical aspects are vital to ensure conducive learning environment. However, the existing layout of the typical classroom in most of Malaysian public schools are not suitable to cater the needs of these learning disable children. In detail, there are two main issues that can be identified on how current Malaysian schools are designed (Ismail \& Abdullah, 2018).

a) Deficiency from non-physical aspects comprising of air quality control, room temperature, lighting and acoustic level.(Ismail \& Abdullah, 2018)

Most of Malaysian classrooms are designed in a typical rectangular style and even with a side opening on both opposing sides of the wall, there is hardly enough air circulation to cool the entire internal section of the classroom especially the central portion. The air circulation conditions in a classroom becomes more critical whenever it rains, as the windows are closed to avoid rain splashes from getting into the classroom. This will result in a closed, noisy, crowded learning space that increase sound decibel in the classroom, combined with the students' and instructors' body heat, leading to a raucous classroom conditions that are also humid and hot. Even though a ceiling fan is available, the air circulation is poor, and indirectly increases the temperature inside the learning space to an uncomfortable level and unconducive for learning. Poor natural lighting also presents in the current classroom design. This is crucial if the classroom block is hidden or blocked by another block that has to utilized artificial lighting. Studies indicate that, students within classroom conditions which are equipped with artificial lighting at a duration exceeding 4 hours and above will easily experience emotional stress, depression as well as the lack of visual stimulation and concentration. Hence, if the classroom view is dark and enclosed student will not be exposed with a significant quantity of natural lighting, therefore they will feel anxiety, disinterest, and hard to focus on the learning task at hand as compared to students situated in a relatively natural lit bright classroom, with extensive light illuminated by natural lighting.

b) Large capacity, size and dense classroom in terms of physical aspect(Ismail \& Abdullah, 2018)

Classroom size and density also influences the behaviour of students. Currently many schools are quite dense and possesses limited space due to the increase in student enrolment every year caused by the rising economy and drastic social development. Hence, the capacity of each study classroom has to support a large amount of students and this causes each space in the classroom to be filled with tables and chairs for the students' use. The result is that there is no space left that can be used for various other activities whether it is for individual or group work as a result of the static and rigid furniture arrangement which is more akin to a traditional/standard classroom characteristic with a row-by-column seating. Other than that, the large number of students in a packed classroom can also affect the students' psychology in that they will exhibit a laziness to mix around, be individualistic, and affect the desire to have an associative attitude, and this will reduce the degree of motivation and creativeness of the students. Furthermore, students will be in a noisy and agitated environment due to the issue of overcrowding.

From the highlighted issues above clearly indicates that from the perspective of encouragement, to date, there is no special design that promotes the development of dyslexia children cognitive and psychomotor development in a comprehensive manner to allow them to stimulate and interact with the existing environment. Since there is no proper design of dyslexic school in Malaysia, the next section will explain on the study methodology and analysis technique using comparative analysis from selected case study at global context to derive the appropriate indicators to produce guidelines in designing better dyslexic school in the Malaysian context in the future.

\section{Methodology}

This study utilises case studies as the research strategy under the framework of qualitative methods and approaches. For data 
collection method, direct observation is used to observed the selected case studies. This is important to answer the study objectives to develop design strategies or guidelines that is suited for the development of conducive learning space for dyslexic children in which focusing on the environment as third teacher concept. The obtained data from observation then is built upon the theories and concepts outlined by Saussure on sign relations, Barthes on levels of signification and Gottdiener on reading the built environment as reliable ways for analysing and understanding the design of classrooms in selected dyslexic schools at the global context. To analyse data from the case study, triangulation technique is used and the data are comparatively analysed and tabulated in table format. All collected data then are finalised to propose the best possible design guideline and strategies for learning space to accommodate the needs of dyslexic children. This is important to achieve the objective of the study. Justification selection on the case study are based upon two main criteria. The first criteria are based on the school category which caters for specific learning disabilities type in terms of curriculum and pedagogy implementation. The second criteria are according to the school approach that portray much emphasis on the implementation of learning environment as third teacher to aid learning disable children namely on the dyslexic patient. This involve the physical and non- physical elements that include multi sensory element involving visual, auditory, kinesthetic and tactile aspects. The finding of the case study will be discussed in Section 4.0. The conducted research framework as in Figure 1.

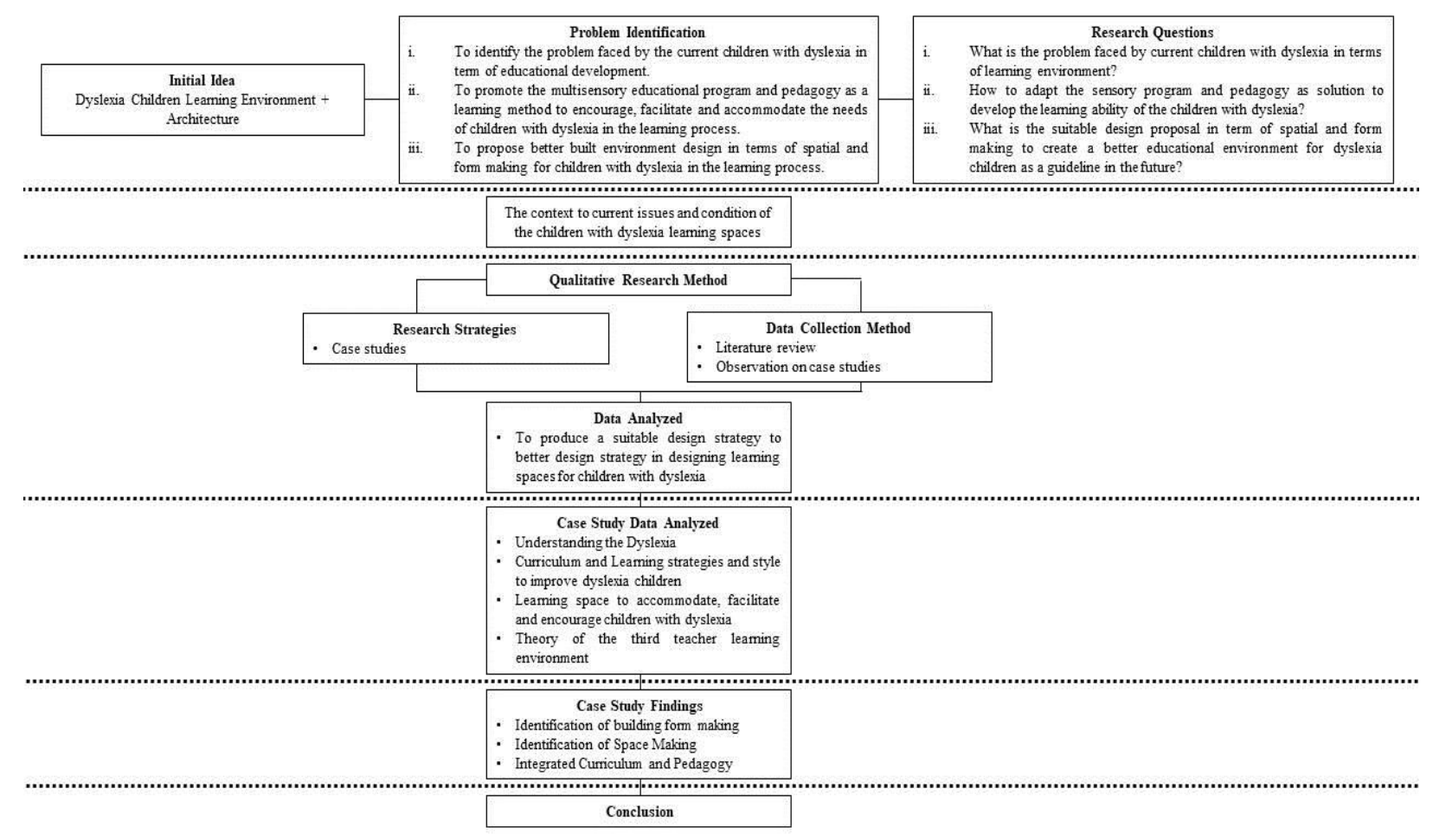

Figure 1 Research framework to conduct the study

\section{Findings}

This section discusses on the findings gathered from observation and literature review on the three selected case study of prominent learning disable school found in global context which are CS1) Pond Meadow School, Guilford CS2) Daaf Geluk School, Netherlands CS3) Stephen Gaynor School, Amsterdam. These three schools are chosen as case study based on the justification of the effectiveness of their applied curriculum and pedagogy as well as the school successfulness in term of addressing the needs of the learning disable children through its unique architectural design in terms of form and space making. The observation on the school learning environment therefore is conducted referring to two main indicators; physical and non physical elements.A1) Non physical elements comprise of A1i) visual A1ii) auditory A1iii) tactile and A1iv)kinaesthetic approaches. A2) Physical elements encompasses of A2i) density and size A2ii) spatial layout. In overall, all three case study did show similarities in their design approach which adopt environment as the third teacher strategy in determining their design scheme. Although these three case studies did not specifically focus on dyslexia students per say but addressing the learning disable children in general. Hence, it can be summarized that learning spaces are important. Therefore, the two aspects of physical and non -physical elements need to be taken into consideration when designing learning space relating to the role of environment as third teacher to promote better social interaction and learning functions. To understand this 
matter in depth, the next section will elaborate further how both of the physical and non physical elements can be adopted and implement in reference to propose design at complex, block and units level in terms of form and space making. (refer Table 2).

Table 2 Findings from case study at global context to derive related indicators in determining design strategies

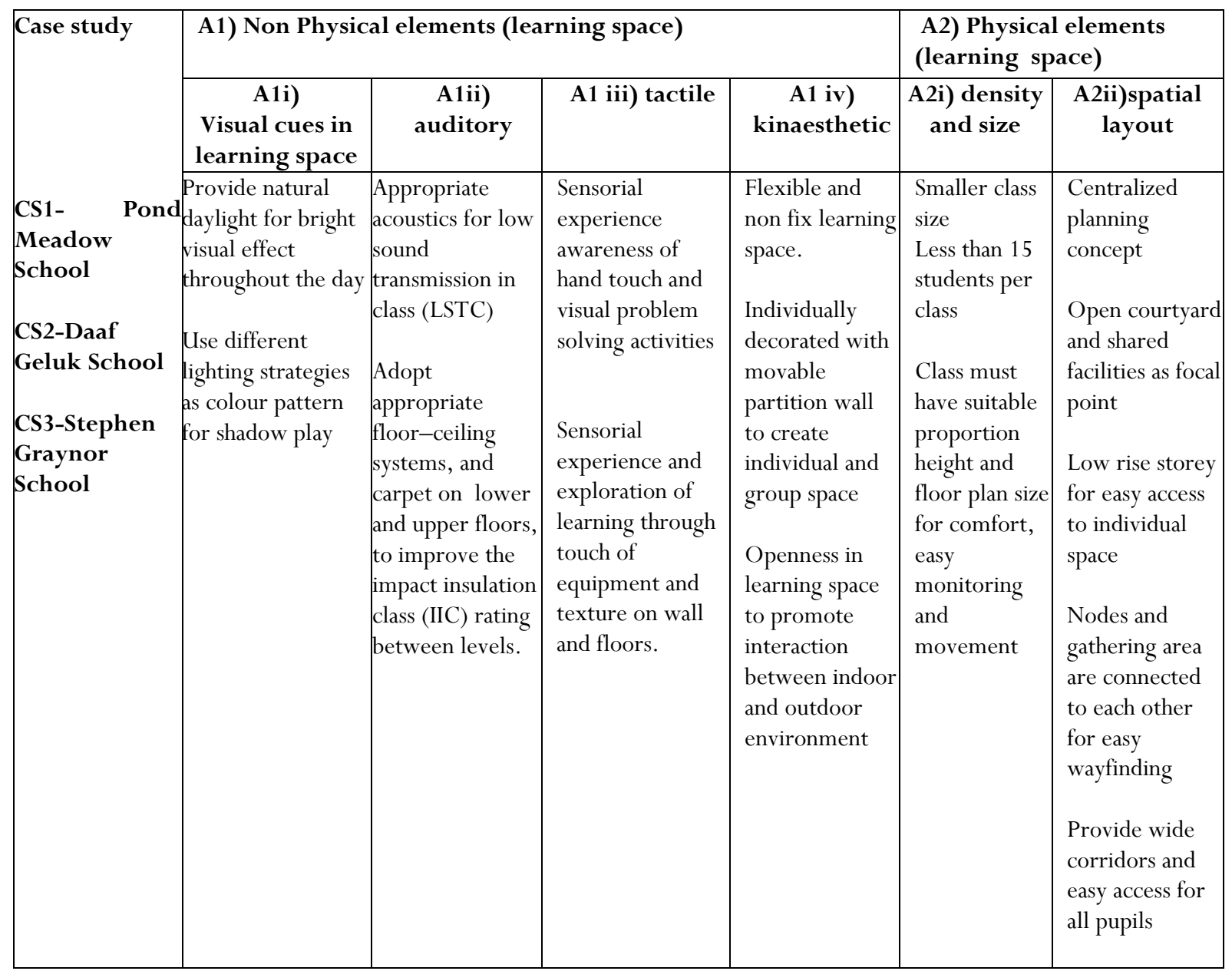

\section{Discussion - Design Strategies And Approaches}

In designing learning spaces for children with dyslexia, it is important to shift away from traditional norm to a more holistic approach that emphasis on the physical and non physical element that shaped the environment for the disable learning children development at the complex, block and unit level. (refer Table 3).
In brief, the implementation of appropriate building components in terms of form and space making is important in designing a learning space for children with learning disability, with consideration to the environment as third teacher to meet the needs of different types of dyslexia for their education betterment. To sum, the guideline in designing an institution for dyslexia children is as in Table 4. 
Table 3 Proposed Design Strategies For Dyslexic Children Learning Spaces At Complex, Block And Unit Level

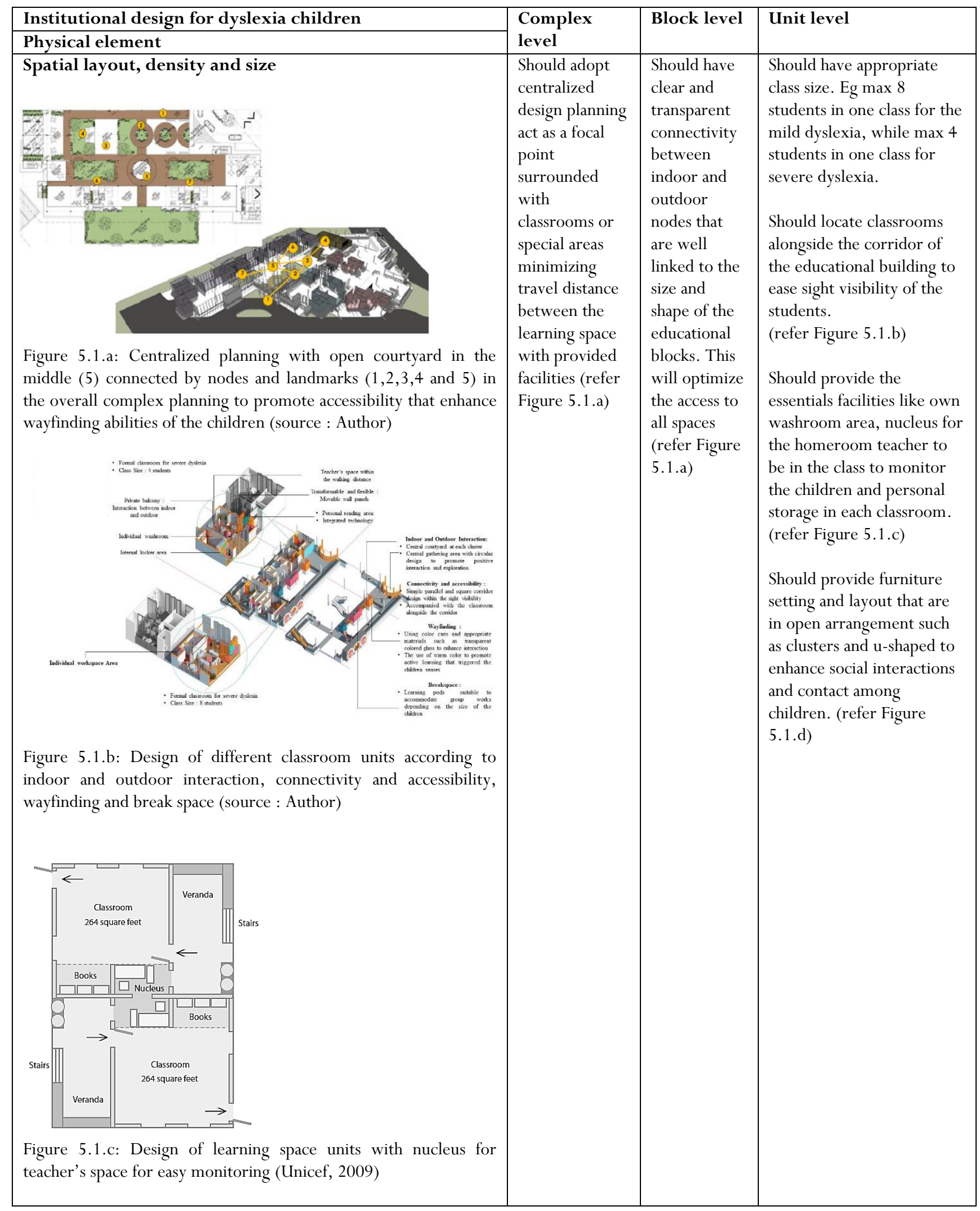




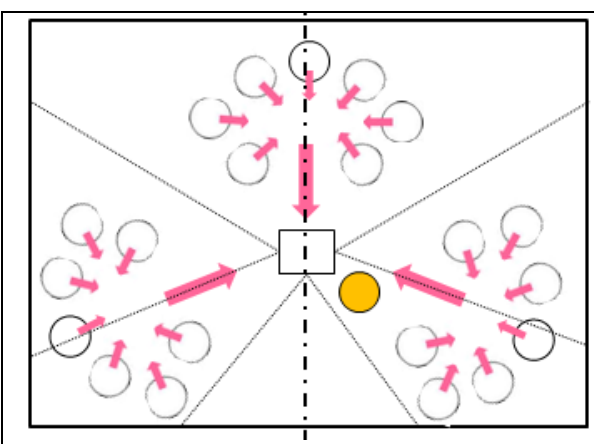

Figure 5.1.d: Furniture setting in class according to multiple projection with students in clusters for flexible learning style (Smith, 2017)

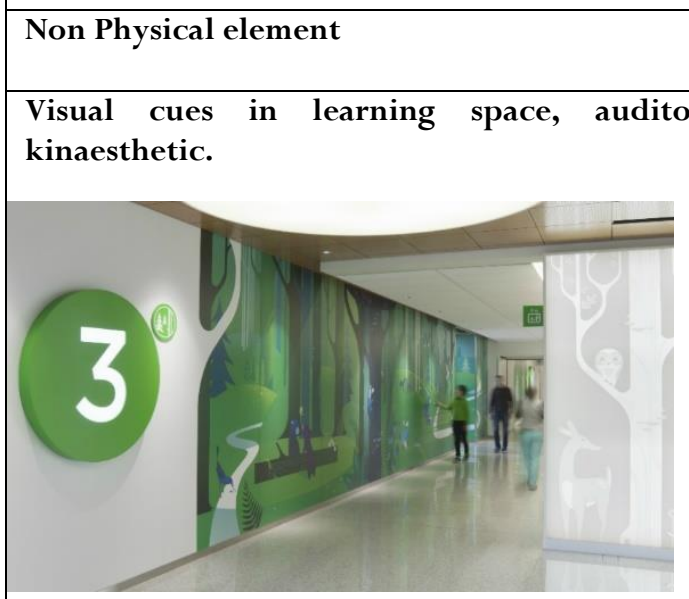

Figure 5.1.e: Visual cues in form of contrasting wall design used for wayfinding (SEGD, 2019)

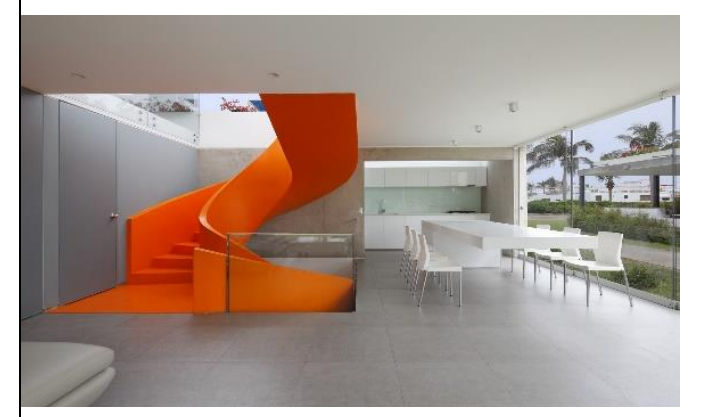

Figure 5.1.f Visual cues in form of contrasting elements like staircase for functional purposes (Studio, 2019)

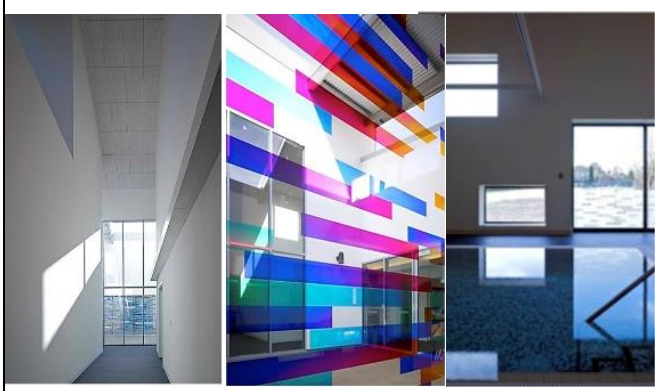

Figure 5.1.g Visual cues in form of lighting strategies to provide visual clarity (DSDHA, 2019)

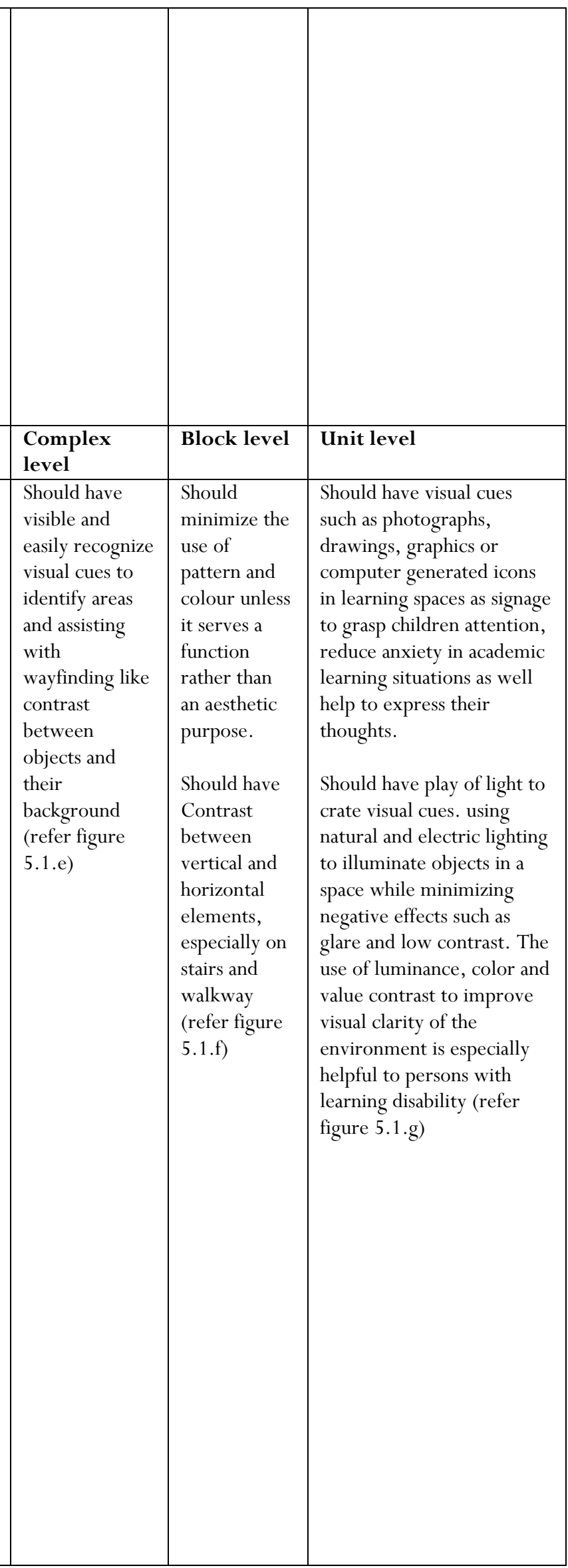




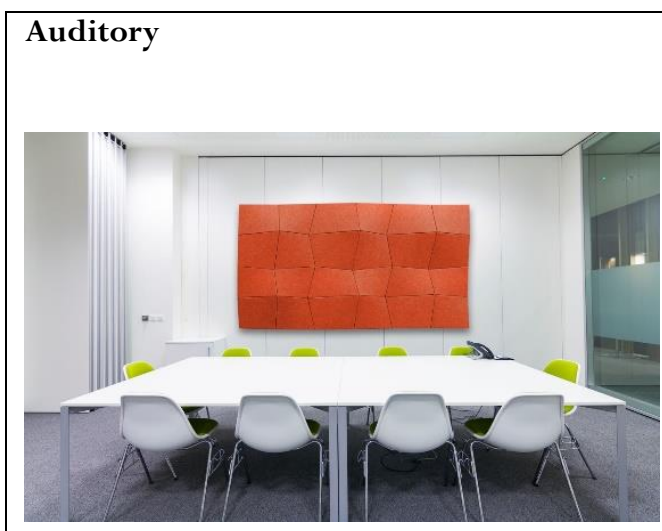

Figure 5.1.h Auditory solution in terms of using sound absorbing wall material as well act as visual cues (Brite, 2011)

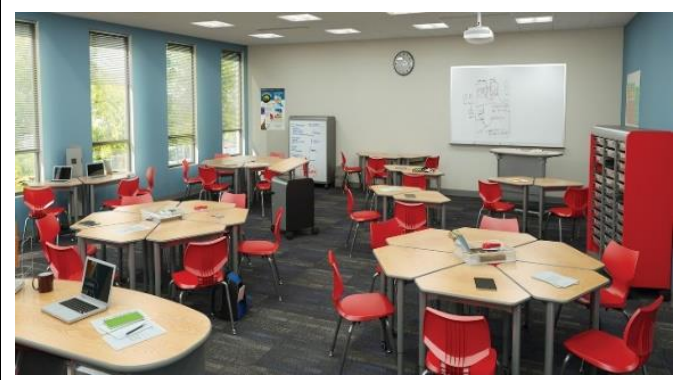

Figure 5.1.i Auditory solution in terms of using sound absorbing flooring material(smithsystem, 2019)

\section{Tactile (materials and texture)}

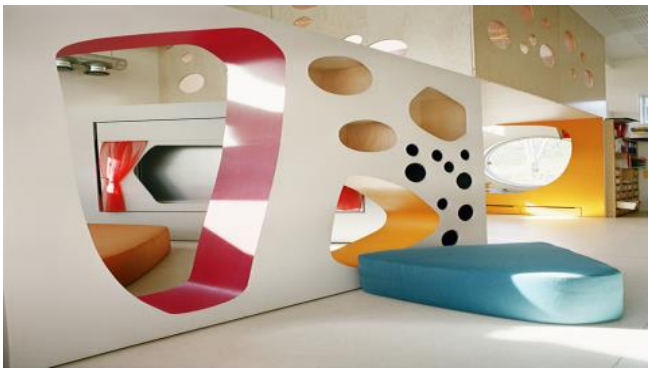

Figure 5.1.j: Usage of different tactile creates visual cues and creativity (Archdaily, 2008)

\section{Kinasthetic (variations and movement)}

Figure 5.1.k: Flexible partition walls that can divide the learning space in multiple layouts (Smith, 2017)

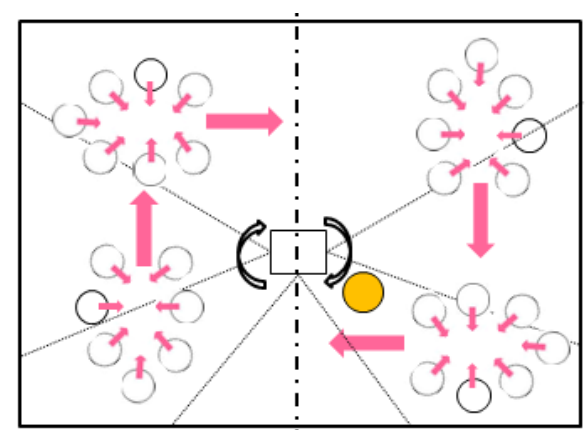

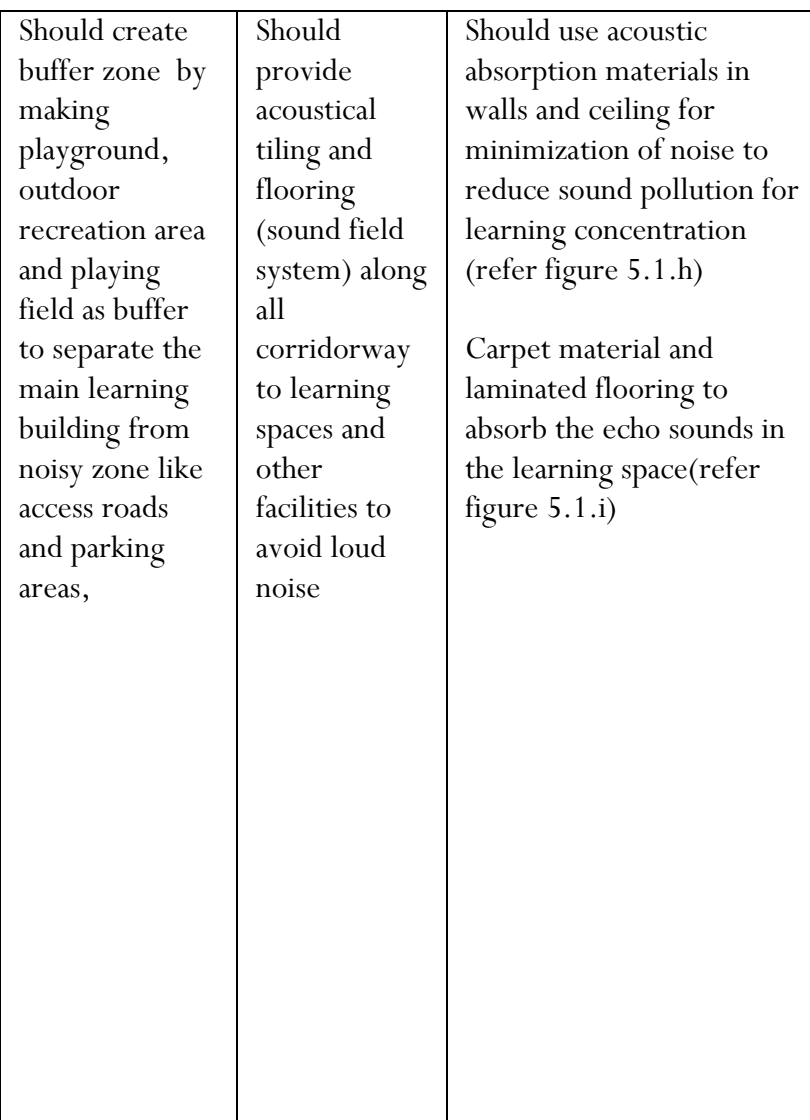

Should use proper material to represent opaque, solid. transparent or hollow outlook to enhance connectivity and provide active social interaction. Example hollow and solid walls at the learning pods provides the sense of curiosity, creativity and connectivity to the surrounding. (refer Figure $5.1 . \mathrm{j})$

Should have flexibility and transformability is where the classroom has installed a movable wall in order for the children to separate the activities according to space and time. (refer Figure 5.1.k) 
Table 4 Design guideline for dyslexic children learning spaces encompassing physical and non physical elements

\begin{tabular}{|c|c|c|}
\hline $\begin{array}{l}\text { Design Elements of Learning } \\
\text { Space (physical and non } \\
\text { physical elements) }\end{array}$ & Description & Explanation \\
\hline Color & $\begin{array}{l}\text { Decorated walls, } \\
\text { bright warm or cool } \\
\text { colors }\end{array}$ & $\begin{array}{ll}\text { - } & \text { Displaying soft stimuli } \\
\text { - } & \text { Spark the children's interests towards learning } \\
\text { - } & \text { Enhance the sense of arrival } \\
\end{array}$ \\
\hline Indoor outdoor relationship & $\begin{array}{l}\text { Interior courtyard } \\
\text { and sensory garden } \\
\text { as flexible spaces }\end{array}$ & $\begin{array}{l}\text { - Learning spaces are located near to the courtyard } \\
\text { - Act as buffer zone to separate different function when is } \\
\text { necessary }\end{array}$ \\
\hline Lighting & $\begin{array}{l}\text { Natural daylighting, } \\
\text { natural shaded, wide } \\
\text { window and door } \\
\text { sizes }\end{array}$ & $\begin{array}{l}\text { - Clear visual from the interior and exterior of the learning } \\
\text { spaces using appropriate materials } \\
\text { - } \quad \text { Punching light to the core of poorly lit spaces and ensure } \\
\text { that there will always have lights at the end of the corridor }\end{array}$ \\
\hline \multirow{3}{*}{ Spatial Layout } & Central courtyard & $\begin{array}{l}\text { Surrounded by classroom and served as an internal link to shared } \\
\text { spaces }\end{array}$ \\
\hline & $\begin{array}{l}\text { Informal } \\
\text { auditorium, } \\
\text { gathering area }\end{array}$ & $\begin{array}{l}\text { Broad wooden staircase function as the school center and a seating } \\
\text { stage act as informal auditorium for the students to gather around. }\end{array}$ \\
\hline & $\begin{array}{l}\text { Location of the } \\
\text { public and private } \\
\text { space zoning }\end{array}$ & $\begin{array}{l}\text { - Located at the end of the building to ensure that it was } \\
\text { provided with its own entrance makes it easier for the } \\
\text { students to access after the school hour. }\end{array}$ \\
\hline \multirow[t]{2}{*}{ Cluster planning } & $\begin{array}{l}\text { Separate by using } \\
\text { two zones one } \\
\text { belong to the upper } \\
\text { class and lower class } \\
\text { connected by the } \\
\text { building shared } \\
\text { facilities. }\end{array}$ & Separate by shared facilities which located at the center \\
\hline & $\begin{array}{l}\text { Basic square and } \\
\text { parallel routing } \\
\text { system }\end{array}$ & $\begin{array}{l}\text { - Runs in parallel routing system and sight visibility. } \\
\text { - Straight and square shapes help the viewer to connect from } \\
\text { the corridor to the existing space. }\end{array}$ \\
\hline Class Size & $\begin{array}{l}\text { Small number of } \\
\text { students in one } \\
\text { class: } \\
\begin{aligned} & \text { a) } \quad 8 \text { students } \\
& \text { for mild } \\
& \text { dyslexia } \\
& \text { b) } 4 \text { students } \\
& \text { for severe } \\
& \text { dyslexia } \\
&\end{aligned}\end{array}$ & $\begin{array}{l}\text { Small distance between speaker and listener to avoid obstruction } \\
\text { along the direct sound path }\end{array}$ \\
\hline Safety and Surveillance & Teacher spaces & $\begin{array}{l}\text { Located inside the classroom and any provided learning spaces to } \\
\text { ensure that teacher is always monitoring the children and in walkable } \\
\text { distance ease to reach whenever in need }\end{array}$ \\
\hline Acoustical & $\begin{array}{l}\text { Acoustical tiling } \\
\text { (sound field system) }\end{array}$ & $\begin{array}{l}\text { - Carpet material, flooring to absorb the echo sounds in the } \\
\text { classroom } \\
\text { - Acoustical flooring installation along the corridor } \\
\text { - Laminated flooring in the art, dance, drama and music } \\
\text { studio gives impact to sound insulations. }\end{array}$ \\
\hline Vertical Zoning & $\begin{array}{l}\text { According to the } \\
\text { curriculum and } \\
\text { school program }\end{array}$ & $\begin{array}{l}\text { - The noisiest area was located at the ground floor as it was } \\
\text { really close to pedestrian street } \\
\text { - Administration and management located below the } \\
\text { academic floor that as a security value in the circulation } \\
\text { building. }\end{array}$ \\
\hline
\end{tabular}




\begin{tabular}{|c|c|c|}
\hline Materials & $\begin{array}{l}\text { Use a proper } \\
\text { material to enhance } \\
\text { connectivity and } \\
\text { provide active social } \\
\text { interaction }\end{array}$ & $\begin{array}{l}\text { - Transparence colored glass at the learning pods provides } \\
\text { the sense of curiosity, creativity and connectivity to the } \\
\text { surrounding visually }\end{array}$ \\
\hline Texture & Ceramic tile walls & Arranged in an asymmetrical fashion to create texture \\
\hline \multirow[b]{3}{*}{ Space Flexibility } & Furniture layout & $\begin{array}{l}\text { According to the different function of the classroom and can } \\
\text { rearrange depends of the suitability of the curriculum and time. }\end{array}$ \\
\hline & $\begin{array}{l}\text { Programs and } \\
\text { curriculum }\end{array}$ & $\begin{array}{l}\text { Combinations of formal lectures, group work and individual work, } \\
\text { flexibility and privacy }\end{array}$ \\
\hline & Learning Breakspace & $\begin{array}{l}\text { - Multiple sizes of the learning pods is placed alongside the } \\
\text { corridor which is } 1.5 \text { to } 2 \text { meters width. } \\
\text { The learning pods are used for the individual or group } \\
\text { works according with the group size and comfort and } \\
\text { privacy level of the students. }\end{array}$ \\
\hline
\end{tabular}

\section{Conclusion}

From the above, it is shown that in designing schools for learning disable children namely the dyslexic, there are two main aspects that contributed to the level of wellbeing of the students. These are the physical elements like density, size and spatial layout. Second, is the non -physical aspect of learning space comprises of visual cues, auditory, tactile and texture as well as kinaesthetic approaches. These aspects are crucial as it could lead to conducive learning and teaching environment. The government and involved authorities should work together with education providers in providing a better learning environment to elevate the education quality for this learning disable students namely the dyslexic children as well as to improve their physical and educational development. This is vital in discovering their full potential to enhance their hidden abilities for better living in the future.

\section{Reference}

Adnan, A. H., \& Hafiz, I. A. (2001). A Disabling Education: The Case Of Disabled Learners in Malaysia. Disability \& Society. 16(5): 655-669.

Ahmad, S. S., Shaari, M. F., Hashim, R., \& Kariminia, S. (2015). Conducive Attributes Of Physical Learning Environment At Preschool Level For Slow Learners. Procedia-Social and Behavioral Sciences. 201: 110-120.

Ali, M. M., Mustapha, R., \& Jelas, Z. M. (2006). An Empirical Study on Teachers' Perceptions towards Inclusive Education in Malaysia. International Journal of Special Education. 21(3): 36-44.

Amar, H. (2008). Meeting the Needs Of Children With Disability In Malaysia. Med J Malaysia. 63(1); 1.

Archdaily. (2008). Classroom Design. Retrieved from http: / /www.archdaily.com/6267/kindergartens-70\%C2\%BAnarkitektur/ Date access: 20 January 2019

Brite, J. (2011). Seeyond Architectural Solutions. Retrieved from https://www.architectmagazine.com/technology/products/seeyondarchitectural-solutions / Date access: 19 January 2019
Brown, M., \& Long, P. (2006). Trends In Learning Space Design. Learning Spaces. 9: 1-9.11.

Démonet, J.-F., Taylor, M. J., \& Chaix, Y. (2004). Developmental Dyslexia. The Lancet. 363(9419): 1451-1460.

DSDHA. (2019). Education. Education. 1st. Retrieved from http: / /www.dsdha.co.uk/projects / Date access: 17 January 2019

Dzalani, H., \& Shamsuddin, K. (2014). A Review of Definitions and Identifications of Specific Learning Disabilities in Malaysia and Challenges in Provision of Services. Pertanika Journal of Social Sciences \& Humanities. 22(1): 1-18

Frith, U. (2017). Beneath the Surface Of Developmental Dyslexia. In Surface dyslexia. 301-330: Routledge.

Goouch, K. (2008). Understanding Playful Pedagogies, Play Narratives And Play Spaces. Early Years. 28(1): 93-102.

Heschong, L., Wright, R. L., \& Okura, S. (2002). Daylighting Impacts On Human Performance In School. Journal of the Illuminating Engineering Society. 31(2): 101-114.

Ismail, A. S., \& Abdullah, S. (2018). Learning Space in Public Secondary Schools for Students Psychological Development and Well Being. International Journal of Engineering \& Technology. 7(3.25): 365374.

Jelas, Z. M., \& Mohd Ali, M. (2014). Inclusive Education In Malaysia: Policy And Practice. International Journal of Inclusive Education. 18(10): 991-1003.

Lyon, G. R., Shaywitz, S. E., \& Shaywitz, B. A. (2003). A Definition Of Dyslexia. Annals Of Dyslexia. 53(1): 1-14.

Malaysia, U. (2014). Children with Disabilities In Malaysia: Mapping The Policies, Programmes, Interventions And Stakeholders. Kuala Lumpur: UNICEF Malaysia.

Muzaliha, M.-N., Nurhamiza, B., Hussein, A., Norabibas, A.-R., Mohd-Hisham-Basrun, J., Sarimah, A., Shatriah, I. (2012). Visual Acuity And Visual Skills In Malaysian Children With Learning Disabilities. Clinical Ophthalmology (Auckland, NZ). 6: 1527. 
Nasir, M. N. A., \& Efendi, A. N. A. E. (2017). Special education For Children With Disabilities In Malaysia: Progress And Obstacles Muhamad Nadhir Abdul Nasir. Geografia-Malaysian Journal of Society and Space. 12(10): 78-87

Oga, C., \& Haron, F. (2012). Life Experiences Of Individuals Living With Dyslexia In Malaysia: A Phenomenological Study. Procedia-Social and Behavioral Sciences. 46: 1129-1133.

Osman, A., Yahaya, W. A. J. W., \& Ahmad, A. C. (2015). Educational Multimedia App For Dyslexia Literacy Intervention: A Preliminary Evaluation. Procedia-Social and Behavioral Sciences. 176: 405411.

Rahman, F. A., Mokhtar, F., Alias, N. A., \& Saleh, R. (2012). Multimedia Elements As Instructions For Dyslexic Children. International Journal of Education and Information Technologies. 6(2): 193200.

Rao, S., Raj, A., Ramanathan, V., Sharma, A., Dhar, M., Thatkar, P. V., \& Pal, R. (2017). Prevalence Of Dyslexia Among School Children In Mysore. International Journal of Medical Science and Public Health. 6(1): 159-164.

SEGD. (2019). A Multidisciplinary Community Creating Experiences That Connect People To Place. What is Wayfinding? 1st. Retrieved from https://segd.org/what-wayfinding/ Date access: 18 January 2019

Sinnadurai, S. L. (2018). Phonological Awareness in Young Bilingual Dyslexics in Malaysia. NTNU,
Smith, C. (2017). The Influence of Hierarchy and Layout Geometry in the Design of Learning Spaces. Journal of Learning Spaces. 6(3): 59-67.

Smithsystem. (2019). Designing the Classroom around the Curiculum. Retrieved from https://smithsystem.com/school-setting/classrooms/ Strong-Wilson, T., \& Ellis, J. (2007). Children And Place: Reggio Emilia's Environment As Third Teacher. Theory Into Practice. 46(1): 4047.

Studio, T. (2019). The Perception Of Color In Architecture. Architecture. 1st. Retrieved from https: / / medium.com/studiotmd/the-perception-of-color-inarchitecture-cf360676776c/ Date access: 17 January 2019

Subramaniam, V., Mallan, V. K., \& Mat, N. H. C. (2013). MultiSenses Explication Activities Module For Dyslexic Children In Malaysia. Asian Social Science. 9(7): 241.

Ta, T. L., Wah, L. L., \& Leng, K. S. (2011). Employability of People With Disabilities In The Northern States Of Peninsular Malaysia: Employers' Perspective. Disability, CBR \& Inclusive Development. 22(2): 79-94.

Tan, S. H. (2015). Development and Psychometric Properties Of A Scale Assessing The Needs Of Caregivers Of Children With Disabilities. Disability And Health Journal. 8(3): 414-423.

Unicef. (2009). Manual: Child Friendly Schools. New York: UNICEF.

Yacob, S. (2005). Maintenance Management System Through Strategic Planning For Public School In Malaysia. Universiti Teknologi Malaysia, 